Bí-grafia: Escritos sobre la Biologia y su Enseñanza Vol. 5 No 9. Monográfico de Evolución. ISSN 2027-1034. Jutio a Diciembre del 2012 P. p. 19-37.

\title{
LA BIOLOGÍA COMO CIENCIA HISTÓRICA: EL CASO DE LA EVOLUCIÓN BIOLÓGICA
}

\section{BIOLOGY AS A HISTORICAL SCIENCE: THE CASE OF BIOLOGICAL EVOLUTION}

Recibido: 21-10-2012

Aceptado: 14-12-2012

\section{Por: Julio Alejandro Castro Moreno}

Resumen. En el texto se discute acerca de en qué sentido la biología puede considerarse como una ciencia histórica. Aunque se argumenta a favor de que un rasgo distintivo de la biología es la historicidad, se dan razones de por qué esta cualidad no se debe únicamente a la historia evolutiva de los organismos. A su vez, se traen a colación dos ejemplos en los que la evolución se ha tomado como lo único que importa en biología, lo cual ha llevado a posiciones dogmáticas. Una forma de salirle al paso a ello es recalcar que la evolución es un proceso contingente y que para ser entendido se requiere acudir a diversos tipos de saberes. Dar cuenta de la complejidad del proceso evolutivo precisa, por otra parte, de la elaboración de narrativas históricas, de las que se explicitan algunas de sus características. El escrito finaliza sugiriendo algunas implicaciones didácticas de los temas antes expuestos.

Palabras clave. Historicidad, contingencia, evolución, narrativas históricas.

Abstract. In this paper we discuss about in what sense Biology can be considered a historical science. Although, we argue in favor of a distinctive feature of Biology, which is its historicity, we consider that there are reasons why this quality is not only due to the evolutionary history of organisms. In turn, we bring two examples in which evolution has been taken as all that matters in Biology, which has led us to dogmatic positions. One way to overcome this is to emphasize that evolution is a contingent process and that to be understood we need to resort to various kinds of knowledge. To account for the complexity of the evolutionary process requires; on the other hand, the development of historical narratives from which we highlight some of their features. The paper ends by suggesting some didactic implications of the topics outlined above.

Keywords. Historicity, contingency, evolution, historical narratives.

La biología ocupa, entre las ciencias, un lugar a la vez marginal y central. Marginal en cuanto que el mundo viviente sólo constituye una parte ínfima y muy «especial» del universo conocido, de suerte que el estudio de los seres vivos no parece poder lograr la revelación de unas leyes generales, aplicables fuera de la biósfera. Pero si la ambición última de la ciencia entera es fundamentalmente, como creo, dilucidar la relación del hombre con el universo, entonces es justo reconocer a la biología un lugar central puesto que es, entre todas las disciplinas, la que intenta ir más directamente al centro de los problemas que se deben haber

${ }^{1}$ Profesor del Departamento de Biología, Universidad Pedagógica Nacional, Bogotá. Doctor en Filosofía de la Ciencia, Universidad Nacional Autónoma de México. Direcciones de contacto: jcastro@pedagogica.edu.co y alecasmor@yahoo.es 
resuelto antes de poder tan sólo plantear el de la «naturaleza humana», en unos términos que no sean metafísicos. Así, la biología es para el hombre la más significativa de todas las ciencias; la que ya ha contribuido, sin duda más que ninguna otra, a la formación del pensamiento moderno, profundamente trastornado y definitivamente marcado en todos los terrenos; filosófico, religioso y político, por el advenimiento de la teoría de la Evolución.

Jacques Monod, El azar y la necesidad.

\section{Introducción}

En la historia y en la filosofía contemporáneas de la biología es común asumir que esta ciencia es, en alto grado, una ciencia histórica, en especial porque se considera que la evolución biológica es la "piedra angular" de la biología o, al menos, una de las disciplinas biológicas más importantes. Ciertamente, como veremos, llevar esta idea a sus últimas consecuencias no solo ha ayudado a consolidar la autonomía de la ciencia de lo vivo, sino que también ha derivado en algunas circunstancias problemáticas, fundamentalmente porque se ha sostenido, desde diferentes puntos de vista, que sin la teoría evolutiva no hay nada que sea comprensible en la biología en su conjunto.

En este orden de ideas, en este artículo me propongo hacer varias cosas. En primer lugar, argumentaré que la biología es, en efecto, una ciencia histórica, pero no exclusivamente histórica, pues hay diferentes formas de emprender la investigación biológica además de las narraciones históricas. Asimismo, mostraré que las otras ciencias de la naturaleza también hacen uso (aunque de distintos modos) del método histórico, pero en la biología este método ha adquirido connotaciones que la hacen sustancialmente diferente de aquellas. Hasta cierto punto, ese método ha tenido importantes desarrollos en las maneras en las cuales hemos entendido que las entidades biológicas (sobre todo las especies) se caracterizan por hacer parte de un devenir histórico marcado por la contingencia. Sin embargo, cabe señalar que la perspectiva histórica en biología no solo tiene asidero en la evolución, sino que otros de sus campos disciplinares, como los estudios sobre la herencia, están igualmente basados en tal perspectiva. Es más: a pesar de que la evolución se fundamenta en la historia, no basta con ello para dar cuenta de la transformación de los organismos a lo largo de vastos periodos de tiempo.

Lo anterior es un insumo para sostener que aunque la historia importa muchísimo en biología, eso no es lo único que cuenta a la hora de hacer indagaciones biológicas. Este asunto, además, nos servirá para argumentar en contra de tomarse en serio frases dogmáticas como la de Dobzhansky acerca de que "nada tiene sentido en biología si no es a la luz de la evolución". En este escrito haré ver que la evolución es muy relevante para entender el mundo viviente, pero que ella no es "totipotente": precisamos de otras formas de hacer biología, y la teoría evolutiva, por su parte, está basada en áreas tan diversas que trascienden el terreno netamente biológico.

En suma, la tesis que defenderé en el presente trabajo es que la biología fundamenta su historicidad en buena medida, pero no de manera total, en la teoría de la evolución, la cual, a su vez, tampoco tiene un carácter puramente histórico. A pesar de ello, en este artículo haré hincapié en el hecho de que la evolución es en alto grado una disciplina histórica y que esto contribuye significativamente a entender la biología como una ciencia histórica. En ese sentido, algunas de las preguntas que orientarán el desarrollo de este escrito son: ¿qué queremos decir cuando afirmamos que la biología es una ciencia 
histórica? ¿Es este su rasgo distintivo y más importante? ¿En qué medida la teoría evolutiva contribuye a fundamentar la historicidad de la biología? ¿En verdad nada tiene sentido en la biología si no nos basamos en la teoría de la evolución? ¿Qué implicaciones para la enseñanza de la biología (y en particular de la evolución) se derivan de las respuestas que demos a las preguntas anteriores?

Así las cosas, el artículo está estructurado de la siguiente manera. En la primera sección abordo el tema de en qué medida la biología es una ciencia histórica aunque no solamente histórica. Lo mismo se argumentará para la disciplina de la evolución biológica. En el segundo apartado veremos cómo una perspectiva que reconoció la historicidad de las entidades vivientes fue uno de los pilares que ayudó a establecer los orígenes de la biología. Lo anterior, sin embargo, ha devenido para algunos autores en un insumo para sostener que sin la teoría de la evolución todo carece de sentido en biología. Por ello, en la tercera sección veremos que quienes sostienen eso han pasado por alto un rasgo distintivo de la historicidad: la contingencia, y que tomarse en serio este aspecto es una buena estrategia para hacer frente a ese tipo de dogmatismos. El tema del cuarto apartado es la importancia de las narrativas históricas, las cuales son las estrategias idóneas para dar cuenta de las características propias del devenir histórico en biología. Finalmente, en la quinta sección, enuncio algunas implicaciones didácticas de la discusión previa.

\section{La biología es una ciencia histórica, pero no es una ciencia exclusivamente histórica}

Estudios recientes en historia y filosofía de la ciencia (y en otras áreas), han puesto de presente que el viejo sueño de unificar la actividad científica con base en lo que se denominó el método científico ha perdido todo su interés. En particular, podemos traer a colación la propuesta que ha desarrollado por casi tres décadas el filósofo lan Hacking acerca de lo que ha denominado como "estilos de razonamiento científico". Aunque abordo con cierto detalle las posibles conexiones entre esa propuesta y la didáctica de la biología en Castro (2011b), aquí vale la pena retomar algo de lo allí discutido. En primera instancia, es importante decir que Hacking sostiene que existen siete estilos, los cuales podemos asumir como siete estrategias generales para hacer ciencia. En breve, ellos son: 1) matemático; 2) experimental; 3) de la modelización analógica; 4) estadístico; 5) taxonómico; 6) histórico-genético y 7) de laboratorio².

Por otra parte, debo agregar que esos estilos no han de confundirse con ciencias o disciplinas particulares, sino que todos ellos son parte constitutivas de la ciencia en su conjunto, fundamentalmente porque los estilos son compatibles y complementarios. En ese sentido, en las investigaciones concretas intervienen algunos estilos o todos ellos. Por ejemplo, en la biología evolutiva podemos evidenciar la siguiente situación:

[Esta disciplina] es a la vez taxonómica e histórica. En ella se hacen experimentos, incluso antes de la era del ADN, por ejemplo con drosófilas. Utilizamos los métodos estadísticos en el análisis de árboles filogenéticos [...] La ley de Hardy y Weinberg es un enunciado sujeto

\footnotetext{
${ }^{2}$ Cabe decir que los primeros seis estilos son retomados por Hacking de la obra del historiador A.C. Crombie, mientras que el séptimo es de su propia cosecha. Una descripción detallada de los estilos de razonamiento se halla en las lecciones que dio Hacking sobre el tema en el Collège de France en la década pasada, cuyos textos están disponibles en esta dirección: http://www.college-de-france.fr/site/historique/ian_ hacking.htm Véase, además, la amplia bibliografía sobre la obra de Hacking citada en Castro (2011b).
} 
al análisis matemático. Dentro de la mayoría de las investigaciones reales, complejas y sofisticadas, utilizamos unos métodos de razonamiento muy variados. Sería muy apropiado considerar el conjunto de esos métodos de razonamiento de los [siete] estilos como una caja de herramientas para las ciencias ${ }^{3}$. (Hacking, 2006, p. 8)

Desde mi punto de vista, es más apropiado entender los estilos como estrategias generales para hacer ciencia (como lo anoté arriba), no como simples herramientas, entre otras cosas porque estas no llegan a ser parte constitutiva de los procesos en los que son usadas. Por otro lado, con la cita anterior podemos empezar a dejar claro por qué a pesar de que la biología evolutiva se caracteriza por ser histórica (allí juega un rol preponderante el estilo histórico-genético), no es solamente histórica, aspecto este que aplica a la biología toda.

Retomando la discusión sobre la compatibilidad de los estilos, es preciso decir que esto no significa que siempre, en cualquier contexto, sean relevantes todos los estilos. Algunos cobran mayor importancia en cierto tipo de investigaciones. Este hecho puede ser ilustrado con lo que planteó James Clarke Maxwell (1831-1879) en sus Scientific Papers, en 1890, con respecto a que la estadística era más importante en física que el método histórico:

Las ecuaciones de la dinámica expresan completamente las leyes del método histórico como aplicadas a la materia, pero la aplicación de esas ecuaciones implica un perfecto conocimiento de todos los datos [...] la porción más pequeña de materia que podemos someter a experimentación consiste de millones de moléculas, ninguna de las cuales llega a ser individualmente perceptible para nosotros. Por lo tanto, no podemos determinar el movimiento real de cualquiera de esas moléculas; así que estamos obligados a abandonar el estricto método histórico y adoptar el método estadístico de tratar con grandes grupos de moléculas. Los datos del método estadístico aplicado a las ciencias moleculares son las sumas de gran número de cantidades moleculares. (Maxwell, 1890, citado por Porter, 1986, p. 111)

Sin duda, los organismos no se comportan como las moléculas: aquellos tienen un devenir histórico del que carecen estas. En los organismos se pueden establecer genealogías, en las moléculas no. Usando terminología de Darwin, en el mundo viviente se lleva a cabo el proceso de "descendencia con modificación", lo cual está ausente del mundo inorgánico. Así entonces, es más fácil usar el método histórico en biología que en física, puesto que en las entidades biológicas hay variaciones hereditarias (y de otras índoles) que las vuelve objeto de selección natural, por ejemplo. También podríamos decir que es más fácil aplicar el método de la estadística a la física que a la biología, entre otras cosas porque hay muchísimos más cuerpos inertes que organismos en el universo y aquellos tienden a comportarse de manera más regular y predecible. ¿Esto significa que la biología es una ciencia histórica mientras que las demás ciencias de la naturaleza no lo son? Por supuesto que no: ello significa que en la biología el estilo histórico adquiere connotaciones que en las demás ciencias no.

\footnotetext{
${ }^{3}$ Esta y todas las citas que provengan de textos escritos en idiomas diferentes al castellano han sido traducidas por el autor del presente artículo.

${ }^{4}$ Vale la pena señalar que Maxwell también contrastó los métodos de la estadística con la experimentación: "La ciencia molecular nos enseña que nuestros experimentos no pueden nunca darnos algo más que información estadística, y que ninguna ley deducida de ellos puede pretender la absoluta precisión. Pero cuando pasamos de la contemplación de nuestros experimentos a la contemplación de las moléculas en sí mismas, dejamos el mundo del azar y el cambio, y entramos en una región en donde todo es certero e inmutable" (citado por Galison, 1987, p. 21).
} 
Es claro que en la química, por poner un caso, también es importante el estilo histórico, por ejemplo en lo que atañe a los procesos de velocidad de reacción o en las técnicas que se emplean para determinar la "vida media" de isótopos radiactivos. Y qué decir de la geología, en dónde el devenir histórico es sumamente relevante. No obstante, en la biología la historia importa mucho más, al punto de que no es descabellado afirmar que este es su rasgo distintivo, porque a diferencia de ciencias como la geología y la química, la contingencia de la historia evolutiva ha dado origen a muchos linajes y a diferentes tipos de adaptaciones que no tienen comparación en las ciencias que se ocupan de lo inerte, en las cuales no hay nada como "descendencia con modificación" (para usar nuevamente un vocablo darwiniano) en las moléculas químicas o en los estratos geológicos. No hay selección natural que permita la "supervivencia" de determinadas poblaciones de rocas ígneas, o extinción (en el sentido biológico) de placas tectónicas. En biología muchas transformaciones son objeto de herencia, y la reproducción sexual, particularmente, es fuente de muchas novedades (genotípicas y fenotípicas), algunas de las cuales se mantienen y otras desaparecen a lo largo de las generaciones. Estas situaciones están ausentes del mundo inorgánico.

Sin embargo, cabe aclarar que el estilo histórico importa mucho en diferentes áreas de la biología, no solo en la evolución. Por ejemplo, como lo afirma López Beltrán $(2004,2007)$, en la configuración de la herencia como un problema científico fueron imprescindibles las historias médicas, pues con base en ellas los médicos alienistas (psiquiatras) franceses, en las primeras décadas del siglo XIX, pudieron establecer la heredabilidad de algunas enfermedades mentales en personas pertenecientes a la misma familia (o a un linaje más amplio). A esto podemos agregar el uso de pedigríes en diferentes contextos como en la crianza de animales y en la medicina humana, y la observación microscópica que ayudó a determinar aspectos sustanciales del desarrollo ontogenético de diferentes clases de organismos. Estas estrategias son claramente históricas.

Pero no está de más llamar la atención acerca de que el "nacimiento" de la biología estuvo marcado, inexorablemente, por el reconocimiento de que las entidades biológicas (como las especies) se caracterizan por transformarse a través de largos periodos de tiempo. En pocas palabras, el surgimiento de la biología como una ciencia autónoma se debió, en gran medida, al cuestionamiento de las ideas de "historia" y "naturaleza" que subyacían en la perspectiva tradicional de historia natural. Dichos cuestionamientos empezaron a cristalizarse a inicios del siglo XIX.

\section{La evolución da cuenta de la historia de los organismos en su curso natural y de la naturaleza viviente en su devenir histórico}

Finalicé un artículo anterior (Castro, 2009a) (palabras más, palabras menos) con la frase que he puesto como subtítulo de esta sección. Con ella quise denotar que la biología, a pesar de que conservó mucho de la tradición naturalista, se distanció de ella notablemente. En particular, la historia natural, que se fundamentó durante mucho tiempo en la propuesta linneana, no era histórica en el sentido en que la biología empezó a serlo a partir de autores como Jean-Baptiste Lamarck (1744-1829) y Charles Darwin (18091882). Recordemos que para Carlos Linneo (1707-1778) las especies (y las demás categorías taxonómicas) eran entidades ahistóricas, creadas de una vez y para siempre, inmunes al paso del tiempo. Cabe decir que en ese escrito asumí que la perspectiva histórica implicada en la transformación de los organismos a lo largo de millones de años 
había surgido con Darwin, pero con base en indagaciones más recientes, sobre todo las que desarrollo en Castro (2011a), debo afirmar que Lamarck ya había dado pasos significativos en esa dirección. No obstante, hay un aspecto que distingue radicalmente las perspectivas de estos autores y que puse de presente en Castro (2005): mientras que el proyecto de Darwin se fundamenta en la contingencia histórica, el de Lamarck no. He de volver sobre este asunto más adelante. Por lo pronto, veamos cómo el nacimiento de la biología corresponde con el reconocimiento de que los organismos sufren transformaciones significativas a través de vastos periodos de tiempo.

Como ha sido dicho en muchos lados, Lamarck fue uno de los autores que en los primeros años del siglo XIX aludió al término "biología", en aras de bautizar una ciencia aún por establecerse. Lamarck escribió varias obras en las que intentó fundamentar la biología, pero es quizá en su Filosofía zoológica en la que más se adentró en el tema. En esa y otras de sus obras, este naturalista hizo algo muy relevante que no podemos perder de vista: abogó por una distinción categórica entre los minerales y los organismos, debido a que argumentaba que dadas sus cualidades distintivas, estos últimos ameritaban una nueva ciencia; la biología. En contraste, en la perspectiva naturalista imperante se asumía que la naturaleza era una, y que todos los "seres" debían ser clasificados en distintos grupos, con base en sus características observables.

Así, al distinguir los organismos de las entidades inertes, Lamarck propuso que aquellos se caracterizan básicamente por dos propiedades ausentes en los minerales: la vida y la organización (Castro, 2011a), características que serían la base más sólida para establecer la nueva ciencia de lo viviente. Pero eso no es todo: Lamarck, además, entendió que la organización progresa a través de grandes periodos de tiempo, por lo que el orden que le conferimos a la naturaleza viviente debe coincidir con los pasos dados en ese devenir. En pocas palabras, Lamarck propone clasificar los organismos con base en cómo se han transformado, empezando con los que él consideraba más complejos y sobre los que sabemos más: los seres humanos. En realidad, lo que él propone es seguir el curso inverso seguido por la naturaleza, desde lo más complejo a lo más simple, lo cual es una estrategia pragmática, no una que dé cuenta de cómo sucedió todo.

De este modo, Lamarck hace frente a dos presupuestos de la historia natural que imperaba en ese entonces: las clasificaciones no deben basarse en sistemas artificiales (como el de Linneo ${ }^{5}$ ) y los organismos son radicalmente diferentes de los seres inertes. Además, puesto que él enfatizó que los organismos tienen una historia que los ha transformado sustancialmente, entonces Lamarck dio tres estocadas mortales a la tradición naturalista de su tiempo: 1) la naturaleza no es una (hay organismos y minerales); 2) la naturaleza viviente no es inmutable, es histórica, y 3) el orden de clasificación ha de coincidir con el curso del progreso de la organización. En suma, con Lamarck se empieza a redefinir lo que entendemos por historia natural, en especial por historia natural de las entidades vivientes.

Cabe agregar que para Lamarck ese devenir histórico estaba impulsado por una tendencia de los organismos al progreso, lo que él denominó "el poder de la vida", lo cual era posible porque en la naturaleza el tiempo no tenía límites. Pero, por otro lado, las circunstancias, siempre cambiantes, en las que se desenvuelven los organismos "obligan" a que estos se transformen en cierta dirección. Como es bien sabido, para Lamarck el

\footnotetext{
${ }^{5}$ En particular porque este autor se basaba en las estructuras sexuales y Lamarck se fundamentaba en el progreso, en la organización.
} 
cambio en las circunstancias implicaba en los organismos nuevos hábitos, los cuales conllevaban nuevas acciones, que a su vez derivaban en el desarrollo o atrofia de órganos, aspecto este que se convertía en objeto de la herencia. En breve, los organismos lamarckianos se adaptan a las condiciones impuestas desde afuera y se esfuerzan por hacerlo heredando lo adquirido, mientras que los organismos darwinianos son seleccionados o no dependiendo de cómo se desenvuelvan en un entorno similar al ambiente en el que sus ancestros inmediatos tuvieron éxito, gracias, en parte, a lo que han heredado de dichos antecesores. En el lamarckismo, el entorno tiene la primera palabra; en el darwinismo pronuncia la última.

Es común suponer que una diferencia fundamental entre las perspectivas de Lamarck y Darwin es que el francés creía en la herencia de los caracteres adquiridos y el inglés no. Quienes sostienen esto han olvidado muy fácilmente, o no se han enterado, que Darwin dedicó mucho tiempo y buena parte de una de sus obras a desarrollar su hipótesis de la pangénesis, la cual se basa, en gran medida, en un supuesto que solo se le quiere atribuir a Lamarck (la herencia de lo adquirido). A mi modo de ver, la ruptura entre lamarckismo y darwinismo se halla en otro lugar: en la idea de contingencia histórica defendida en este último proyecto 6 .

Ciertamente, no podemos perder de vista que un autor contemporáneo de Lamarck, Charles Lyell (1797-1875), le confirió a la Tierra una edad de miles de millones de años, gracias a sus trabajos en geología, y con eso estaba ayudando a establecer la historicidad no solo del mundo viviente, sino del inerte. Pero hay que señalar que la perspectiva de Lyell (como la de Lamarck) carece de un elemento que es vital para lo que entendemos por evolución biológica: la contingencia histórica. Recuérdese que para dicho autor las causas que han actuado en el pasado son las mismas que operan en la actualidad: una roca es horadada debido a que continuamente caen gotas de agua sobre ella, y esto ha venido ocurriendo desde tiempos antiquísimos. En fin, las mismas causas interviniendo de manera inmutable a lo largo del tiempo. Sin duda, los trabajos de Lyell y los de Lamarck (estos en menor medida) fueron un sustento fundamental para establecer la obra darwiniana, pero en esta la contingencia está en el centro de la explicación.

Como lo desarrollo en Castro (2009b), la idea de evolución subyacente en el proyecto darwiniano está signada, inexorablemente, por la contingencia histórica. Como lo muestro en ese trabajo, basándome en autores como Beatty (1995) y Gould (1995), la idea de fondo es que los procesos evolutivos que hemos reconstruido y los que podríamos reconstruir, al menos en parte, no están guiados por leyes inmanentes y mucho menos por designios divinos. Como lo apunta Gould, aludiendo a su famoso "experimento mental", si pudiésemos rebobinar la cinta de la película que llamamos "evolución" y la pusiéramos a andar nuevamente, no tendríamos ninguna razón para esperar un desenlace idéntico, ni siquiera igual. No cabría esperar el surgimiento de nuestra propia especie y mucho menos asumir, como en ocasiones se ha hecho, que esta es la cúspide de la evolución. Así las cosas, la contingencia da cuenta de las bifurcaciones, de las transformaciones, del origen de nuevas especies y también de la extinción de otras tantas. No hay un progreso lineal que nos lleve a la complejidad, sino diversas trayectorias históricas que conducen a diferentes manifestaciones de la complejidad. En suma, la contingencia nos permite entender dos aspectos de los procesos históricos: la imprevisibilidad y la irrepetibilidad, a los que regresaré en la cuarta sección.

\footnotetext{
${ }^{6}$ Sin duda existen otras rupturas entre las perspectivas de estos autores, pero me interesa resaltar esta. Una discusión sobre otras discontinuidades entre Lamarck y Darwin se encuentra en Castro (2005).
} 
Aunque parezca inconcebible, uno de los más famosos "neodarwinistas" del siglo XX, Theodosius Dobzhansky (1900-1975), pasó por alto el hecho de que la evolución es un proceso contingente, pero a la vez quiso asumir que sin la evolución nada tenía sentido en biología. En el siguiente apartado explico cómo ello ha sido posible y propongo una salida a dicha paradoja.

\section{La contingencia histórica como antídoto al dogmatismo de Dobzhansky}

Como nos lo muestra la evidencia histórica, no han sido pocos los intentos de posicionar el darwinismo, o al menos versiones muy particulares de él, en un lugar privilegiado en la biología, lo cual, como veremos, ha dado como resultado planteamientos dogmáticos que en nada contribuyen a entender, en toda su complejidad, la historicidad de los procesos evolutivos. Uno de tales intentos fue el de Ernst Haeckel (1834-1919), en la segunda mitad del siglo XIX, con lo que denominó "la ley biogenética" o, como es más conocida, "la recapitulación": "La ontogenia es la breve y rápida recapitulación de la filogenia". Esta doctrina fue propuesta en 1866 en el contexto evolucionista (supuestamente inspirado en Darwin).

No está de más anotar que a pesar de que Haeckel hizo trabajo experimental en un momento de su vida ${ }^{7}$, su idea de recapitulación estuvo basada, exclusivamente, en la observación y comparación de organismos adultos y de embriones. Por eso, su perspectiva era netamente morfológica y formal (no funcional), la cual empezó a ser cuestionada cuando, a finales del siglo XIX, en la embriología se introdujeron técnicas experimentales de la física y la química, deviniendo así mecanicista y experimental. Una de las primeras voces que se alzaron en contra del proyecto recapitulacionista fue la de Wilhelm His (1831-1904), quien en 1874 se lamentaba de la vacuidad causal de la que adolecía tal proyecto. His denominó a su propuesta como "embriología fisiológica", término que luego cambió por el de "mecánica del desarrollo" (Mechanik der Entwicklung) (Gould, 2010).

De acuerdo con Gould (2010, p. 231), los morfólogos formales y los embriólogos funcionales estaban destinados a entrar en conflicto. Para los primeros lo que importaba eran las huellas de la filogenia, las cuales se evidenciaban en las formas embrionarias. A los segundos, por su parte, les interesaban las causas próximas del desarrollo embrionario. Así, para Haeckel y su escuela la causa de una etapa embrionaria era remota y eficiente, mientras que para los embriólogos funcionales las causas eran próximas y eficientes. En consecuencia, el primer bando se valía de la observación del desarrollo normal y la comparación de diversos estadios en diferentes grupos de organismos, mientras que el segundo bando se basaba en la intervención experimental de los procesos normales, para ver qué ocurría con el desarrollo.

Podemos asumir que la postura de Haeckel era dogmática en la medida en que este autor no aceptaba otra explicación que no fuera la de la primacía de la filogenia:

\footnotetext{
${ }^{7}$ Por ejemplo, en 1869 publicó los resultados de la división experimental de larvas de sinóforos, los cuales demostraban que las medias larvas obtenidas eran capaces de formar organismos enteros (Oppenheimer, citado por Gould, 2010, p. 239).
} 


\begin{abstract}
El defecto principal de este método «exacto» o fisiológico [...] en embriología se advierte en su intento de reducir los procesos históricos más complejos a simples fenómenos físicos [los cuales] no comprendemos realmente hasta que seguimos su pista hasta sus verdaderas causas filogenéticas, y vemos que cada uno de estos procesos aparentemente simples es la recapitulación de una serie de cambios históricos [...] El conocimiento histórico no puede ser sustituido por ninguna otra rama de la ciencia. (Haeckel, 1905, citado por Gould, 2010, pp. 237-238, cursivas en el original)
\end{abstract}

Por supuesto que el conocimiento histórico no puede ser reemplazado por otro, pero también es cierto que este tipo de conocimiento no es autosuficiente. Debido a los vacíos explicativos de la perspectiva "recapitulacionista", no es extraño que algunos investigadores tomaran partido por situarse en el otro extremo, al pretender explicar la ontogenia únicamente por medio de la experimentación. Así, entre finales de la década de 1880 e inicios del decenio siguiente, Wilhelm Roux (1850-1924) y Hans Driesch (18671941), "dos estudiantes apóstatas" de Haeckel (como los denomina Gould), empezaron a promover métodos experimentales en embriología, lo que conllevó que la ley biogenética llegara a ser considerada como algo obsoleto. Desde esta perspectiva, Roux y otros presentaron un nuevo programa de investigación en embriología con el que desafiaron al enfoque filogenético reinante, el cual llamaron "mecánica del desarrollo" (Entwicklungsmechanik): el experimento era ahora la clave para comprender las causas del desarrollo; lo importante eran las causas mecánicas, no las causas filogenéticas.

Desde luego que en estas tensiones entre los embriólogos "formales" y "experimentales" podemos ver que lo que está en disputa es el tipo de historia que se está priorizando: el de corta duración de la ontogenia o la de largo alcance de la filogenia. Hoy en día, me parece, este tipo de tensiones están siendo superadas desde el proyecto que se ha denominado como "evo-devo", asunto que no desarrollaré aquí. Basta decir, en aras de retomar mi línea de argumentación, que en cualquier caso estamos presenciando instancias de la biología como ciencia histórica.

No sobra recalcar que calificar a la biología como una ciencia histórica no tiene por qué llevarnos a afirmar que lo único relevante en esta ciencia es su carácter histórico, representado fundamentalmente por la teoría evolutiva. Vimos que esto no pudo ser el caso en las tensiones entre los defensores de la ontogenia y los de la filogenia, a finales del siglo XIX, pero ya bien entrado el siglo XX hubo otro intento de "dogmatizar" la evolución, al sostener que sin ella no hay nada que tenga sentido en la biología en su conjunto. Como ya se habrá advertido, me estoy refiriendo a la famosa frase de Dobzhansky, la cual, desafortunadamente, está muy arraigada en diferentes áreas que tienen que ver con la ciencia de lo vivo, como en la historia, en la filosofía y, sin duda, en la enseñanza de la biología.

Hay varias maneras de entender el "nuevo darwinismo" defendido por Dobzhansky como un dogma. Destaco dos de ellas: la primera es la que ya he mencionado, que toda explicación en biología ha de ser, en última instancia, una explicación evolutiva, lo cual nos conduce a una posición reduccionista que no comparto. La segunda atañe al ámbito religioso-ideológico, con el que tampoco estoy de acuerdo, al asumir que la evolución es un medio que Dios utiliza para llevar a cabo la creación. En cualquier caso se trata de dogmas, pues se alude a posiciones cimentadas en actos de fe, no en evidencias que podamos contrastar y/o cuestionar. Por esas razones, en Castro (en dictamen) denominé a la frase de Dobzhansky ("Nada en biología tiene sentido si no es a la luz de la evolución") como el dogma central de la síntesis evolutiva (DCSE). En lo que sigue retomaré algunas de las discusiones planteadas en el mencionado artículo. 
Un punto que vale la pena traer a colación es que el DCSE fue planteado por Dobzhansky como título de una conferencia que dio en una reunión de la American Association of Biology Teachers a inicios de la década de 1970 (Burian, 2005, p. 104), cuyo texto se publicó, usando el mismo título "Nothing in Biology Makes Sense Except in the Light of Evolution" (Dobzhansky, 1973), en una de las más prestigiosas revistas sobre enseñanza de la biología en el ámbito anglosajón: The American Biology Teacher. Retomaré este asunto luego. Por el momento me interesa argumentar por qué es hora de abandonar el DCSE.

En contra de la dimensión reduccionista del DSCE a la que aludí arriba, cabe decir que la evidencia histórica nos enseña que la teoría evolutiva no hubiese sido posible sin algunos avances en diversas áreas, muchas de las cuales no son parte de las ciencias naturales. Solo a modo de ejemplo podemos mencionar las siguientes: la teoría económica de Adam Smith (1723-1790); los estudios demográficos de Thomas Malthus (1766-1834); las técnicas de hibridación, crianza y selección de horticultores y ganaderos, entre otros; los hallazgos en geología, sobre todo en lo que respecta a la edad de la Tierra y a los procesos de fosilización, etc. Como lo muestro en Castro (2004), la obra El origen de las especies, en la que se establecen las bases de lo que hoy asumimos por evolución biológica, tuvo muchos orígenes, algunos de los cuales son los que acabo de enlistar.

$\mathrm{Si}$, además, nos percatamos de los sustentos biológicos de la teoría evolutiva, como la paleontología, la taxonomía, la embriología y la anatomía comparadas, la bioquímica, la biología molecular y un largo etcétera, podemos concluir que sin estos soportes esa teoría no se hubiese podido formular ni desarrollar del modo en que lo ha hecho. Así las cosas, no es que la biología solo sea comprensible desde un marco evolutivo, sino que este es plausible únicamente bajo el concurso de diferentes áreas (biológicas o no). Recuérdese, asimismo, la cita de Hacking que traje a colación al inicio de este artículo, para reforzar la idea de que la disciplina que llamamos biología evolutiva no es solamente una disciplina histórica. Pero con esto no quiero sugerir que la evolución sea irrelevante en biología, sino que esta no es autosuficiente, como lo asumía Dobzhansky. En pocas palabras, no es que nada carezca de sentido en biología sin una explicación evolucionista, sino que gracias a la evolución todo en biología puede ser más comprensible (Castro, 2009b, y en dictamen).

Por otra parte, debo decir que las connotaciones más desafortunadas del DCSE, a mi modo de ver, son las que se derivan del ámbito religioso-ideológico del mismo. Aunque en Castro (en dictamen) hago un análisis pormenorizado del artículo de Dobzhansky (1973), vale la pena citar aquí un apartado de tal trabajo:

La diversidad orgánica llega a ser, sin embargo, razonable y comprensible si el Creador ha creado [sic] el mundo viviente no por capricho, sino a través de la evolución propulsada por selección natural. Es erróneo sostener que la creación y la evolución son alternativas mutuamente excluyentes. Yo soy un creacionista $y^{8}$ un evolucionista. La Evolución es el método de creación de Dios o de la Naturaleza. La creación no es un evento que ocurrió en el año 4.004 A.C.; éste es un proceso que empezó hace aproximadamente 10.000 millones de años y aún está en marcha. (Dobzhansky, 1973, p. 127. Énfasis míos)

Podría pensarse que como Dobzhansky fue uno de los "arquitectos" de la síntesis evolutiva (en la década de 1930), entonces su famosa frase (el DCSE) no es más que una

\footnotetext{
${ }^{8}$ Este énfasis es del original.
} 
estrategia para resaltar el papel preponderante que juega la evolución en la biología, pero quienes piensen esto evidentemente no han leído el artículo en el que dicho eslogan fue propuesto. Desde mi punto de vista, el DCSE no es darwinista, puesto que en él se pone en el centro de la explicación la intervención de fuerzas de otro mundo (léase la mano de Dios), algo totalmente diferente a lo que Darwin mismo se propuso hacer: "Si he errado en dar a la selección natural un gran poder, lo cual estoy muy lejos de admitir, o en haber exagerado su poder, lo cual es en sí mismo probable, al menos, como espero, he hecho un buen servicio al ayudar a echar abajo el dogma de las creaciones separadas" (Darwin, El origen del hombre, citado por Gould, 1982, p. xvii. Cursivas añadidas). Para Darwin, evolución (selección natural) era antónimo de creación divina, no algo totalmente equiparable a este supuesto, como sí lo creía Dobzhansky.

Pero eso no es todo. Dobzhansky creía también que la evolución transcurría teleológicamente, en particular porque pensaba que el punto culminante de la dupla evolución-creación era nuestra propia especie:

El hombre, el pináculo de la evolución. Una de las maneras más sencillas de satisfacer nuestro ego es considerarnos superiores a otros. Por esta razón, la opinión que el hombre se encuentra en el escalón más alto de la escalera del progreso debe ser escudriñada con cuidado. Sucede, sin embargo, que por medio de todos los criterios sensibles de progreso el hombre es superior a las otras criaturas [...] la evidencia concluyente sobre la posición superior del hombre es que en él, y solamente en él, ha evolucionado el genotipo que lo faculta para desarrollar y mantener una cultura. La cúspide biológica del hombre es una eminencia solitaria; ninguna otra especie puede aspirar a disputársela. (Dobzhansky, 1955, citado por Araújo, 2000, p, 27)

Así pues, podemos inferir que Dobzhansky no asumió la evolución como un proceso contingente, pues para él este ponía en marcha la creación planeada por Dios, la cual tenía un fin último: el ser humano. Pero es posible afirmar que desde una perspectiva darwinista lo teológico y lo teleológico son totalmente opuestos a lo contingente. En consecuencia, el DCSE no es un postulado darwiniano, porque no toma en serio lo afirmado por el propio Darwin. Dicho lo anterior, propongo resaltar el aspecto contingente de la evolución en aras de hacerla más comprensible: entre otras cosas, la contingencia histórica del proceso evolutivo nos permite evidenciar que este se lleva a cabo a través de ramificaciones y que ninguna de esas ramas ha de entenderse como superior a las otras. Recuérdese que el único esquema que usó Darwin en El origen de las especies fue un árbol (que hoy llamamos filogenético) 9 . Como lo afirma Gould: "La evolución es un árbol, no una escalera" (1986, p. 69). Vimos, en la cita anterior de Dobzhansky, que ese autor asumía la evolución como una escalera, cuyo último peldaño estaba ocupado por el ser humano.

En esta sección he expuesto cómo una posición como la de Dobzhansky deviene dogmática, y que una forma de hacerle frente es reconocer que la evolución es ante todo un proceso histórico que se caracteriza por la contingencia. Este hecho, a su vez, debe ser tomado muy en serio a la hora de elaborar narraciones que den cuenta de ese transcurrir histórico.

\footnotetext{
${ }^{9}$ Es importante decir que la idea de evolución, o si se quiere de transformación, como un devenir ramificado, ya estaba presente en Lamarck, aunque como dije atrás la propuesta de este autor no está marcada por la contingencia. En particular, Lamarck estableció tres tipos de bifurcaciones: 1) entre minerales y organismos, 2) entre animales y vegetales y 3 ) entre algunas clases de animales (Castro, 2011a).
} 


\section{La importancia de las narraciones históricas}

De acuerdo con Gould (1986, p. 60), Darwin fue sobre todo un innovador en cuanto a la forma de proceder, pues incursionó en una nueva metodología: la histórica ${ }^{10}$, que no había jugado un rol importante en los estudios sobre lo vivo. En pocas palabras, Darwin nos enseñó a emplear el método de la historia como otra forma de hacer ciencia (diferente a la centrada en el experimento y la observación, por ejemplo). Aunque es bueno recalcar que, como lo expuse en la primera sección, podemos asumir que hay al menos siete formas básicas o generales de hacer ciencia, las cuales, siguiendo a Hacking, llamamos estilos de razonamiento científico. Así, una de esas formas de emprender la actividad científica es el estilo histórico, y una manera de poner en acción dicho estilo es a partir de la elaboración de narraciones que hagan plausible la explicación de eventos del pasado (remoto o cercano). Podría suponerse que las explicaciones históricas son totalmente disímiles de otro tipo de explicaciones, como las estadísticas, como queda patente, por ejemplo, en las palabras de Maxwell citadas en el primer apartado. Sin embargo, aunque este pueda ser el caso en física, no lo es ni en biología ni en medicina, como lo ha argumentado López Beltrán (1998b, 2007).

En particular, este autor ha dicho que existe una continuidad, tanto conceptual como histórica, entre dos tipos de explicación que tradicionalmente se han considerado como opuestas e incompatibles: las estadísticas y las narrativas. Asimismo, él ha señalado que a las primeras se les ha concedido un estatus científico, especialmente por estar basadas en la cuantificación y por estar soportadas en un razonamiento probabilista, mientras que a las segundas se les "tacha" de subjetivas, de estar sustentadas en lo anecdótico, lo particular y lo contingente. Por el contrario, continúa López Beltrán, en buena medida las estadísticas solo se pudieron consolidar gracias al cúmulo de narrativas que se han acopiado durante siglos y, en ese sentido, aquellas tienen una estructura narrativa que con el tiempo se ha hecho implícita. En suma, como lo sostiene el autor en mención, las estadísticas son otra forma de contar historias, pero ese es un tema que no desarrollaremos aquí.

En este momento es importante decir que Hacking, a pesar de haber insistido en que todos los estilos son compatibles y complementarios, ha sugerido que el estilo histórico no es explicativo, y quizá esa sea una de las razones por las cuales no ha usado las palabras "narrativa" o "narración" para describir dicho estilo (Hacking, 2010). Este hecho se ve reforzado con lo que este autor plantea en el siguiente pasaje: "Los fenómenos acerca de las especies -por ejemplo el hecho de que una manada de leones caza con el macho rugiendo desde su guarida mientras que las hembras persiguen y matan a una gacela asustada- son anécdotas. Pero los fenómenos de la física -el efecto Faraday, el efecto Hall, el efecto Josephson- son las llaves que abren el universo" (Hacking, 1996, pp. 256257).

Este menosprecio de Hacking por lo que él llama "anécdotas" puede ser controvertido a partir de lo que han planteado diversos autores. En particular, Martínez (1997) ha mostrado detalladamente la manera en que históricamente se han desarrollado en la ciencia distintos patrones de explicación, los cuales no tienen por qué verse como incompatibles o jerarquizados. Por ejemplo, Martínez discute ampliamente sobre lo que

\footnotetext{
${ }^{10} \mathrm{Y}$, como vimos, la historia se caracteriza por ser contingente, a diferencia de lo planteado en el proyecto lamarckiano.
} 
denomina explicaciones históricas, narrativas y seleccionistas y, en ese sentido, podemos decir que para dar cuenta del comportamiento de los leones debemos acudir a este tipo de explicaciones que, a mi modo de ver, nos abren las puertas a otros aspectos del mundo a los que difícilmente entraríamos con los efectos físicos aludidos por Hacking: "El hecho importante es que las generalizaciones en la teoría de la evolución no pueden desligarse de ciertos aspectos históricos o contextuales que permiten que la generalización sea una generalización con valor explicativo" (Martínez, 1997, p. 156. Cursivas en el original).

Como ya anoté, Hacking ha afirmado que el estilo histórico no es explicativo, debido a que él se basa en el modelo de explicación desarrollado por Hempel ${ }^{11}$, para quien debe haber una simetría entre la explicación y la predicción y, como sabemos, las narrativas están lejos de ser predictivas, en gran medida porque se construyen a partir de la contingencia de la historia, razón por la cual las narrativas solo pueden dar cuenta de eventos únicos e irrepetibles. Pero este no era el caso para Hempel, ya que él incluso sostuvo que existían leyes probabilistas que permitían no solo explicar eventos históricos sino, además, predecirlos. A mi modo de ver, no hay leyes históricas, si por eso entendemos enunciados universales, necesarios y altamente matematizables, que den cuenta del transcurrir histórico.

Recuérdese que según Gould, si devolvemos la cinta de la película evolutiva y la echamos a andar nuevamente, no hay ninguna razón para esperar que todo vuelva a ocurrir del mismo modo. Si existiesen tales "leyes hempelianas" en la historia, la película de desenvolvería siempre del mismo modo. Obviamente, estamos aludiendo a un "experimento mental", como lo reconoce el mismo Gould, pues no podemos devolver el tiempo y permitir que vuelva a andar hacia "adelante". Pero no es menos cierto que la historia escapa a la predicción y a la "repetibilidad": los hechos históricos son únicos, aunque puede haber patrones de sucesos que nos permitan catalogarlos como haciendo parte de un mismo patrón. No obstante, el punto que quiero resaltar aquí es que las narrativas históricas son las estrategias idóneas para explicar los procesos evolutivos.

Sin duda, las narraciones no solo desempeñan un papel en la explicación de la evolución biológica, sino que estas toman lugar en otras áreas del saber. Por ejemplo, como lo ha señalado Epstein (1995), los médicos son contadores de historias, pues ellos examinan e interrogan a sus pacientes, a partir de lo cual producen una narrativa de la historia de los enfermos, crean así un registro de casos, por lo que en un sentido muy básico los doctores son historiadores, son cronistas de un cuerpo de eventos y son, además, narradores sistemáticos de fenómenos particulares en contextos específicos. Es desde esta perspectiva que Epstein sostiene que el saber médico tiene una estructura narrativa, a la cual denomina como "narratividad" (p. 25). Me parece que esta noción es útil para explicar la estructura narrativa del conocimiento evolutivo, por lo que la retomaré en este apartado.

No es difícil afirmar que cualquier explicación histórica, como las que están implicadas en hacer plausibles distintas trayectorias filogenéticas, está signada por la narratividad, la cual, a su vez, está estructurada por relaciones de causa-efecto que toman cuerpo en una dimensión temporal. En ese sentido, como lo argumenta López Beltrán (1998a), las narrativas no son simples secuencias o listados de eventos, ya que su concatenación temporal no necesariamente se ciñe a lo estrictamente cronológico, sino que ello conlleva

\footnotetext{
${ }^{11}$ Véase, por ejemplo, Hempel (1979).
} 
que dichos episodios se hilvanen causalmente. Aquí lo causal no significa que un evento determine la ocurrencia de otro que lo prosigue en el tiempo, sino que el antecede fue una de las múltiples causas que posibilitaron su existencia. Lo causal configura la espina dorsal de las narrativas: "(...) si no existe ningún tipo de hilo causa-efecto, por imaginativo o retorcido que sea, en la relación entre los estados iniciales y finales, la eficacia del relato disminuye" (López Beltrán, 2007, p. 201). Esta espina dorsal causal en la evolución atañe, por ejemplo, a las relaciones de ancestría-descendencia en un linaje a lo largo de un vasto periodo de tiempo. He aquí de nuevo la importancia de la "descendencia con modificación".

Sin embargo, cabe señalar que al aludir a hilos causa-efecto no estamos comprometidos con una idea lineal del cambio histórico y del cambio evolutivo en particular. Como quedó patente en el apartado previo, el devenir evolutivo ha de entenderse como una trayectoria arborescente. Así, de acuerdo con Richards (1998, p. 218), es posible hablar de unidades constitutivas de una narración mayor, las cuales conforman un todo. A dichas unidades narrativas las denomina "narremas". Podemos afirmar, desde este punto de vista, que las historias de vida de los individuos pertenecientes a la misma especie (al mismo linaje) son los "narremas" de una historia más general o filogenia. En este caso, y según Hull (1998, p. 266), para dar cuenta, por ejemplo, del devenir de un linaje humano, no se trata simplemente de enunciar quién se casó con quién y quiénes engendraron a quiénes: la historia de un linaje no es la mera suma de las historias personales, sino que estas se integran en una sola narración. Esto es lo que Hull llama explicaciones integrativas de las narraciones.

En síntesis, la estructura narrativa o narratividad del conocimiento histórico en general, y del conocimiento evolutivo en particular, solo es comprensible a partir de las narraciones históricas en las cuales se entrelazan diversas historias individuales (narremas) para configurar una historia más abarcadora, como lo es una filogenia. Pero, a su vez, diversas filogenias se vinculan de forma arborescente, lo que nos lleva a concluir que una trayectoria histórica, como los diversos procesos evolutivos, no se produce de manera lineal sino ramificada. Además, dichos procesos están marcados por la contingencia, aspecto este que implica irrepetibilidad e imprevisibilidad. Todas estas características solamente pueden ser articuladas como un todo gracias a la construcción de narraciones históricas. Así las cosas, estas estrategias deberían hacer parte de los programas en los que se pretende enseñar la teoría evolutiva, en especial en los currículos para la formación de profesores de biología.

\section{Algunas implicaciones didácticas de la historicidad de la evolución biológica}

En este apartado haré referencia a las implicaciones que tiene la discusión previa en la formación inicial y avanzada de profesores de biología, en especial porque todos los esfuerzos que podamos hacer para cualificar la educación de este tipo de profesionales redundarán positivamente en los procesos de enseñanza-aprendizaje de la biología en los diferentes niveles educativos. Obviamente, cuando aludo a profesores de biología no quiero decir con esto que los temas que he desarrollado en este artículo den cuenta de la enseñanza de dicha ciencia en su conjunto, sino particularmente de la enseñanza de la evolución, pero, ¿qué otros profesionales serían los responsables de semejante tarea sino los profesores de biología? Me dirijo a ese gremio, además, porque fue el mismo al que Dobzhansky propuso su famosa frase, la cual, como hemos visto, devino un dogma difícil de erradicar tanto de la biología como de su enseñanza. 
Podemos afirmar que la comprensión (e incluso aceptación) de la evolución ha tenido que sortear diferentes tipos de obstáculos, desde Darwin o antes de él. Uno de ellos ha sido el "dogma de las creaciones separadas", para retomar otra frase darwiniana. Otro de ellos, muy ligado con el anterior, es poder asumir procesos graduales (a veces no tanto) que se llevan a cabo a lo largo de millones o miles de millones de años. Un antídoto al primer obstáculo, como lo vimos en la tercera sección, es tomarnos en serio la idea de que la historia es contingente y que, en ese sentido, estamos aquí y ahora no por un designio divino que nos puso en la cúspide de la escalera, sino debido a un proceso natural, carente de sentido, único e irrepetible, que nos ha colocado en una de las innumerables ramas del árbol de lo vivo.

Postular una estrategia para superar el segundo obstáculo tal vez sea más complicado, pero sin duda esta tendrá que estar sustentada en lo que Mayr ${ }^{12}$ ha denominado como "pensamiento poblacional", en íntima comunión con lo que aquí denominaré "pensamiento histórico". El pensamiento histórico no es otra cosa que una forma de razonamiento que dé cuenta de la estructura narrativa del conocimiento histórico (la narratividad), en particular del conocimiento evolutivo. Como se habrá advertido, una manera de ayudar a consolidar dicho tipo de pensamiento es a partir de la elaboración de narrativas, o por medio del estudio de las narrativas elaboradas por otros.

Precisamente esta es una de las estrategias que proponemos en Castro y Valbuena (2007, pp. 139-140) como una forma de aprender y enseñar biología. Como lo sostuvimos en ese artículo, un modo de propiciar la elaboración y/o comprensión de narrativas es a partir de la historia de la ciencia, en particular acerca de cómo han procedido personajes como Darwin. En ese orden de ideas, vale la pena recordar lo que afirmé páginas atrás acerca de que, según Gould, una de las innovaciones más importante de dicho naturalista fue la de introducir el método histórico en la explicación de lo que él llamó "descendencia con modificación". Asimismo, es importante decir que el mismo Gould ha sostenido que ese método ha sido menospreciado en diferentes ámbitos, como el de la enseñanza de la ciencia, por poner un caso:

La ciencia histórica es aún ampliamente mal comprendida, subestimada o denigrada. La mayoría de los jóvenes primero se hallan ante la ciencia, en su educación formal, aprendiendo acerca del poderoso modo de razonamiento llamado "el método científico". Más allá de unos pocos tópicos acerca de la objetividad y la disposición a cambiar su mentalidad, los estudiantes aprenden un estrecho estereotipo sobre la observación, la simplificación de probar aparte variables controladas, el experimento crucial y la predicción con repetición como un test [...] Así, cuando los estudiantes se enfrentan luego a la historia, donde los eventos complejos ocurren solamente una vez [...] ellos solamente pueden concluir que tal asunto debe ser menos que ciencia. $Y$ cuando los estudiantes se aproximan a la diversidad taxonómica, o a la historia filogenética, o a la biogeografía donde el experimento y la repetición tienen aplicación limitada a los sistemas en su totalidad- ellos sólo pueden concluir que se hallan ante algo indigno de la ciencia, frente a algo meramente "descriptivo". (Gould, 1986, p. 64)

No sobra reiterar que, como hemos visto en las secciones previas, no se trata de decir que en biología, y específicamente en biología evolutiva, de lo que se trata es de asumir al método histórico (o al estilo histórico-genético, como lo denomina Hacking) como la única forma adecuada de emprender indagaciones que nos permitan dar cuenta del

${ }^{12}$ Véase, por ejemplo, Mayr (2006). 
devenir histórico de las especies. No se trata de caer en posiciones dogmáticas, como las de Haeckel o Dobzhansky, mediante las cuales se asume que la historia evolutiva es lo único que importa. De lo que se trata, entonces, es de reconocer el papel importantísimo de la historia, cuyo rasgo distintivo es la contingencia. Narrar la historia evolutiva de los organismos no es lo mismo que contemplar cómo se despliega la creación, planeada y puesta en marcha por Dios a través de la selección natural, como lo creía Dobzhansky. Narrar la historia evolutiva de los organismos es tomarse en serio el hecho de que la naturaleza viviente es histórica y no admite la intervención de fuerzas de otro mundo.

Asumir una historia natural de los organismos tiene importantes implicaciones didácticas que no podemos pasar por alto. Una de ellas es reconocer que nuestra propia especie hace parte de esa historia, lo que nos vincula filial y naturalmente con las demás especies que existen y han existido en este planeta. En ese sentido, merece la pena traer a colación una pregunta que han planteado Bizzo y El-Hani (2009): ¿por qué deberían los estudiantes aprender evolución? A lo que han dado varias respuestas, dentro de las cuales destaco las siguientes: discutir las consecuencias éticas del hecho de estar genealógicamente relacionados con los demás organismos, y evidenciar los vínculos históricos entre el surgimiento de la biología y la propuesta de la teoría evolutiva. Sobre la última respuesta argumentamos ampliamente en el segundo apartado, mientras que sobre la primera podríamos añadir que si asumimos que somos el "producto" de un proceso natural y no de un diseño divino (y menos aún que nos hallamos en la cúspide de la creación), este hecho nos obliga a repensar nuestro lugar en el mundo, como lo anunciaba Monod en la frase que usé como epígrafe.

Desde luego que de la exposición previa podemos extraer otras posibles implicaciones para la enseñanza de la evolución, como por ejemplo las que atañen a las formas en que es abordado este tema en los libros de texto (Castro, 2003) o el lugar que ocupa en el diseño curricular. No insistiré en estos asuntos, pero sí lo haré en lo que respecta a que si fundamentamos la formación y cualificación de profesores de biología en los discursos histórico-filosóficos de esta ciencia, ello redundará en que los enseñantes comprendan de una manera más compleja qué han hecho, por qué, para qué y cómo, los científicos que han producido la ciencia que pretenden enseñar. La historia y la filosofía de las ciencias no son herramientas para enseñar mejor, sino marcos de referencia que nos permiten entender de una manera más real, por ponerlo en esos términos, la ciencia que será objeto de enseñanza-aprendizaje en diferentes contextos y niveles educativos. La enseñanza de la evolución no puede ser la excepción: si deseamos asumir esa tarea, una ayuda importantísima se halla en los discursos histórico-filosóficos de dicha disciplina biológica.

\section{Conclusión}

En este trabajo he argumentado que la biología es una ciencia histórica que se diferencia de otras como la geología, porque aquella se distingue por un proceso ausente en esta: la descendencia con modificación, término usado por Darwin para nominar lo que hoy llamamos evolución. Sin embargo, asumir que la biología es histórica no tiene por qué llevarnos a asumir que esto se debe solamente a que las entidades vivientes evolucionan a lo largo de grandes periodos de tiempo, sino que otros ámbitos biológicos, como la embriología y la herencia, por poner dos casos, se caracterizan por sustentarse en explicaciones históricas. A esto hay que añadir que ni la ciencia biológica ni la disciplina de la biología evolutiva son exclusivamente históricas, aunque sí lo son en alto grado. 
En ese orden de ideas, el hecho de afirmar que la historia importa para entender la biología, no implica que la teoría evolutiva sea lo único que cuente en la ciencia de lo vivo, pues, como vimos, este tipo de posiciones nos pueden conducir a defender dogmas, como los defendidos por Dobzhansky. A propósito de este autor, es importante cuestionar lo que aquí denominé el DCSE, en especial porque fue propuesto ante un auditorio conformado por profesores de biología, y porque se publicó (en 1973) en la que quizá es la revista más importante para la enseñanza de la biología en el contexto angloparlante. Así las cosas, me he dirigido a los docentes de biología con la intención de analizar críticamente las implicaciones de los postulados de Dobzhansky, no solo en la biología sino fundamentalmente en su enseñanza.

Así como en la biología no es cierto que nada tenga sentido si no es a la luz de la evolución, sino que esta ayuda a hacerlo todo más comprensible, del mismo modo no debemos asumir que en la enseñanza de la biología lo único realmente importante es la enseñanza de la evolución, sino que esta hace más plausible, compleja e interesante la enseñanza de la biología en su conjunto. Asimismo, una estrategia para complejizar la enseñanza de la evolución es acudir a la historia y a la filosofía de la biología, ámbitos que, como hemos expuesto, nos ayudan a comprender cómo se han constituido los saberes que hoy consideramos dignos de ser enseñados. La evolución, como lo afirma Monod, no ha de entenderse desde presupuestos metafísicos, sino que, diría yo, ha de asumirse con los pies bien puestos sobre esta Tierra que transitamos juntos, como individuos efímeros y como especies un poco más longevas.

\section{Referencias}

Araújo, A.M. (2000). Imanência e transcendência na evolução biológica: a visão de Theodosius Dobzhansky. Episteme, Porto Alegre, v. 11, p. 21-36. Disponible en: http://www.ilea.ufrgs.br/episteme/portal/index.php

Beatty, J. (1995). The Evolutionary Contingency Thesis. In G. Wolters \& J. Lennox (Eds.), Concepts, Theories and Rationality in the Biological Sciences. The Second PittsburgKonstanz Colloquium in the Philosophy of Science. Pittsburg University Press.

Bizzo, N. \& El-Hani, C.N. (2009). Darwin and Mendel: Evolution and Genetics. Journal of Biological Education, v. 43, n. 3, p. 108-114.

Burian, R. (2005). "Nothing in Biology Makes Sense Except in the Light of Evolution" (Theodosius Dobzhansky). In Burian, R. The Epistemology of Development, Evolution, and Genetics. Selected Essays (pp. 103-125). New York: Cambridge University Press.

Castro, J.A. (2003). Libros de texto: historia y filosofía de las ciencias. Nodos y Nudos, 15, 4-18.

Castro, J.A. (2004). Los orígenes del Origen de las especies. Tecné, Episteme y Didaxis, 16, 47-63.

Castro, J.A. (2005). De Lamarck a Darwin: ¿continuidad o ruptura? ¿Linealidad o bifurcación? Tecné, Episteme y Didaxis, 17, 75-92. Disponible en: http://www.pedagogica.edu.co/revistas/ojs/index.php/TED 
Castro, J.A. (2009a). Tradición naturalista y museos de historia natural: ¿qué naturaleza? ¿Cuál historia? Una reflexión desde la historia de la biología. Bio-grafía. Escritos sobre la biología y su enseñanza, vol. 2 (2). Disponible en http://www.pedagogica. edu.co/revistas/ojs/index.php/bio-grafia/index

Castro, J.A. (2009b). La idea de contingencia histórica como eje central del darwinismo. Una discusión en torno a la actualidad de Darwin. Bio-grafía. Escritos sobre la biología y su enseñanza, vol. 2 (3). Disponible en http://www.pedagogica.edu.co/revistas/ojs/index. php/bio-grafia/index

Castro, J.A. (2011a). Vida y organización: dos conceptos centrales en la biología de Lamarck. Propuestas para un nuevo lamarckismo. Ludus Vitalis, vol. XIX, n. 35, 49-71.

Castro, J.A. (2011b). Estilos de razonamiento científico y enseñanza de la Biología: posibles conexiones y propuestas didácticas. Revista de Educación en Biología (REB), Volumen 14, Número 2, 5-12. Disponible en: www.revistaadbia.com.ar

Castro, J.A. (En dictamen). ¿Nada en biología tiene sentido si no es a la luz de la evolución? Artículo sometido a evaluación en Ciência \& Educação, Bauru, Brasil.

Castro, J.A. y Valbuena, E. (2007). ¿Qué biología enseñar y cómo hacerlo? Hacia una resignificación de la Biología escolar. Tecné, Episteme y Didaxis, 22, 126-145. Disponible en: http://www.pedagogica.edu.co/revistas/ojs/index.php/TED

Dobzhansky, T. (1973). Nothing in Biology Makes Sense Except in the Light of Evolution. The American Biology Teacher, 35, 125-129.

Epstein J. (1995). Altered Conditions. Disease, Medicine, and Storytelling. New York: Routledge.

Galison, P. (1987). How Experiments End. Chicago: The University of Chicago Press.

Gould, S.J. (1982). Introduction. In Dobzhansky, T. [1937] Genetics and the Origin of Species. 3 ed. (pp. xvii-xxxix). New York: Columbia University Press.

Gould, S.J. (1986). Evolution and the Triumph of Homology, or Why History Matters. American Scientist, vol. 74, 60-69.

Gould, S.J. (1995). La vida maravillosa: Burgess Shale y la naturaleza de la historia. Barcelona: Crítica.

Gould, S.J. (2010) [1977]. Ontogenia y filogenia. La ley fundamental biogenética. Barcelona: Crítica.

Hacking, I. (1996) [1983]. Representar e intervenir. Trad. Sergio Martínez. México: PaidósInstituto de Investigaciones Filosóficas, UNAM.

Hacking, I. (2006). Objets. Chaire de philosophie et histoire des concepts scientifiques. Collège d e France. Disponible en http://www.college-de-france.fr/media/historique/UPL32 $\underline{423 \text { objets.pdf }}$ 
Hacking, I. (2010). III-B Historical Derivation. Texto de la lectura dada en el Instituto de Investigaciones Filosóficas, UNAM, el 27 de abril de 2010.

Hempel, C. (1979) [1942]. La función de las leyes generales en la historia. En: Hempel, C. La explicación científica. Barcelona: Paidós.

Hull, D. (1998). Sujetos centrales y narraciones históricas. En: S. Martínez y A. Barahona (Comps.), Historia y explicación en biología (pp. 247-272). México: Universidad Nacional Autónoma de México y Fondo de Cultura Económica.

López Beltrán, C. (1998a). Narrativa y explicación en las ciencias naturales. En: S. Martínez y A. Barahona (Comps.), Historia y explicación en biología (pp. 197-211). México: Universidad Nacional Autónoma de México y Fondo de Cultura Económica.

López Beltrán, C. (1998b). Explicación narrativa y explicación estadística en medicina y biología. En: S. Martínez y A. Barahona (Comps.), Historia y explicación en biología (pp. 275-288). México: Universidad Nacional Autónoma de México y Fondo de Cultura Económica.

López Beltrán, C. (2004). In the Cradle of Heredity; French Physicians and L'Hérédité Naturelle in the Early 19th Century. Journal of the History of Biology, 37, 39-72.

López Beltrán, C. (2007). Narrativa, estadística y pensamiento hereditario. El soporte narrativo de las primeras estadísticas. En: Suárez, E. (Comp.). Variedad infinita. Ciencia y representación: Un enfoque histórico y filosófico (pp. 189-213). México: Limusa y Universidad Nacional Autónoma de México.

Martínez, S. (1997). De los efectos a las causas. Sobre la historia de los patrones de explicación científica. México: Paidós-UNAM.

Martínez, S, y Barahona, A. (Comps.). (1998). Historia y explicación en biología. México: Universidad Nacional Autónoma de México y Fondo de Cultura Económica.

Mayr, E. (2006). Por qué es única la biología. Consideraciones sobre la autonomía de una disciplina científica. Buenos Aires: Katz.

Porter, T. (1986). The Rise of Statistical Thinking 1820-1900. Princeton: Princeton University Press.

Richards, R. (1998). La estructura de la explicación narrativa en historia y biología. En: S. Martínez y A. Barahona (Comps.), Historia y explicación en biología (pp. 212-246). México: Universidad Nacional Autónoma de México y Fondo de Cultura Económica. 